\title{
la nueva arquitectura brasileña
}

ALBERTO SARTORIS, arquitecto

En el movimiento actual de la construcción, la contribución del Brasil moderno es tal vez la primera realización emprendida a gran escala para definir una arquitectura nacional. En un nivel extremadamente elevado, brillantes creadores de calidades insólitas, se han mostrado capaces de establecer los más diversos ejemplos de esta construcción $\mathrm{y}$ de hacer de sus audaces proyectos una serie de nuevos conocimientos que forman parte importante de la civilización contemporánea.

Las tendencias de la arquitectura racional se manifestaron en Brasil como una bomba.

Se ha desarrollado con una fuerza inaudita y ha adquirido una velocidad de expresión de la cual no existe probablemente otro ejemplo en el mundo.

Pero este relámpago arquitectónico, que podía haber tenido sólo efectos transitorios, ha aparecido en un ambiente propicio, lo que le ha permitido imponerse inmediatamente e implantarse firmemente en un suelo fértil.

No obstante, el ritmo fulminante de su crecimiento y las formas fulgurantes que ha imaginado tienen algo de milagro y de leyenda. De una envergadura extraordinaria, la arquitectura brasileña de hoy - como la de los tiempos de las basílicas romanas y de las catedrales góticas-

amplifica los principios europeos y mediterráneos, dándoles dimensiones gigantescas, proporciones a la medida de su naturaleza espectacular, la de sus plantas enormes y sus paisajes inmensos.

Dos acontecimientos han contribuído poderosamente al nacimiento

de la arquitectura funcional brasileña. El primero, de orden espiritual:

la influencia ejercida por las ideas innovadoras de los centros

de vanguardia de nuestro Continente; el segundo, de orden político: la Revolución de 1930, de la cual ha nacido el gobierno actual.
Por otra parte es interesante señalar que ya, antes de la obra de saneamiento acabada por la escuela brasileña moderna, con excepción de ciertos edificios de carácter oficial,

la arquitectura pasaba, casi sin transición, de la casa colonial, de una o dos plantas, al rascacielos. También se nota que al principio de la arquitectura moderna se seguían todavía los principios estrictos de los modelos europeos. 
No contenía nada de carácter particularmente nacional. Sus rascacielos no son otra cosa que sólo casas más altas.

Pero entonces, de golpe, su autonomía se realiza.

Este comienzo categórico se localiza en el año 1927 , cuando Gregori J. Warchavchik construyó, en Sâo Paulo, la primera casa moderna de Brasil.

En cuanto a la parte técnica, económica y estética de la arquitectura contemporánea, se observa que los arquitectos brasileños han establecido los principios de sus construcciones modernas, primero por el análisis

de las formas de la plástica arquitectónica y de las formas resistentes de las estructuras descendientes de los métodos europeos, y luego, basando la realización de sus invenciones en las condiciones económicas particulares y en la situación de su país.

Al principio, el trabajo de la arquitectura moderna fué obstruído por el hecho de que el hierro,

el acero, el cristal, el mármol y el cemento (y, a veces, hasta la piedra) eran materiales de importación, lo cual aumentaba considerablemente el precio de la construcción. Por otra parte, una industria aún poco desarrollada no era capaz de producir, en cantidad, los aparatos sanitarios, tubería, pinturas, barnices, elementos prefabricados y materiales

de revestimiento, en calidad y cantidad suficiente. En cambio,

ladrillos de excelente calidad y maderas espléndidas permitieron construir, a un ritmo rápido, edificios cuya vida estaba calculada con una duración limitada de veinte a treinta años.

Desde hace unos años, Brasil-cuyo movimiento de renovación es esencial en la evolución de la arquitectura racional de la América latina, y que tiene el aspecto prometedor de una civilización-ha creado su propio estilo, un estilo absolutamente nacional, bajo la dirección de arquitectos excepcionales, tales como: Lucio Costa, Oscar Niemeyer, Rino Levi, Enrique Ephim Mindlin, Affonso Eduardo Reidy, Roberto Burle Marx, Joâo Vilanova Artigas, Marcelo, Mauricio y Milton Roberto, citando sólo un número muy pequeño de ellos.

Las reservas que se han manifestado en cuanto a las obras de Oscar Niemeyer,

el gran pionero de la arquitectura funcional brasileña, no están basadas en ningún argumento consistente. Se ha hablado, y bastante mal,

de barroquismo, del amor a la forma por la forma, de arquitectura exclusivamente estética, de geometría gratuita, de nuevo rococó privado de ornamentación, todo ello cierto, buscando arbitrariamente volúmenes bizarros, composiciones fantásticas y extravagantes.

De este importante período febril y creador de Niemeyer era, sin embargo, fácil decir que representaba un fenómeno soberano de readaptación de la arquitectura al espíritu de la fantasía libre que caracteriza la tradición brasileña, formada antes bajo la influencia de las arquitecturas portuguesa y española.

Esta etapa de gran valor de Niemeyer, nos deja construcciones monumentales con líneas suaves, onduladas y sinuosas, las cuales tenían como propósito principal

la multiplicación de superficies tanto en planta como en alzado. Estas construcciones muestran también la voluntad de trazar una arquitectura de estructura personal con un carácter doblemente marcado, es decir, a la vez por la tradición y por lo nuevo.

Durante el desarrollo prodigioso de las ciudades de Sâo Paulo y de Río de Janeiro, la arquitectura brasileña ha levantado conjuntos de líneas de gran sobriedad, llenas de movimiento y dinámicas. 


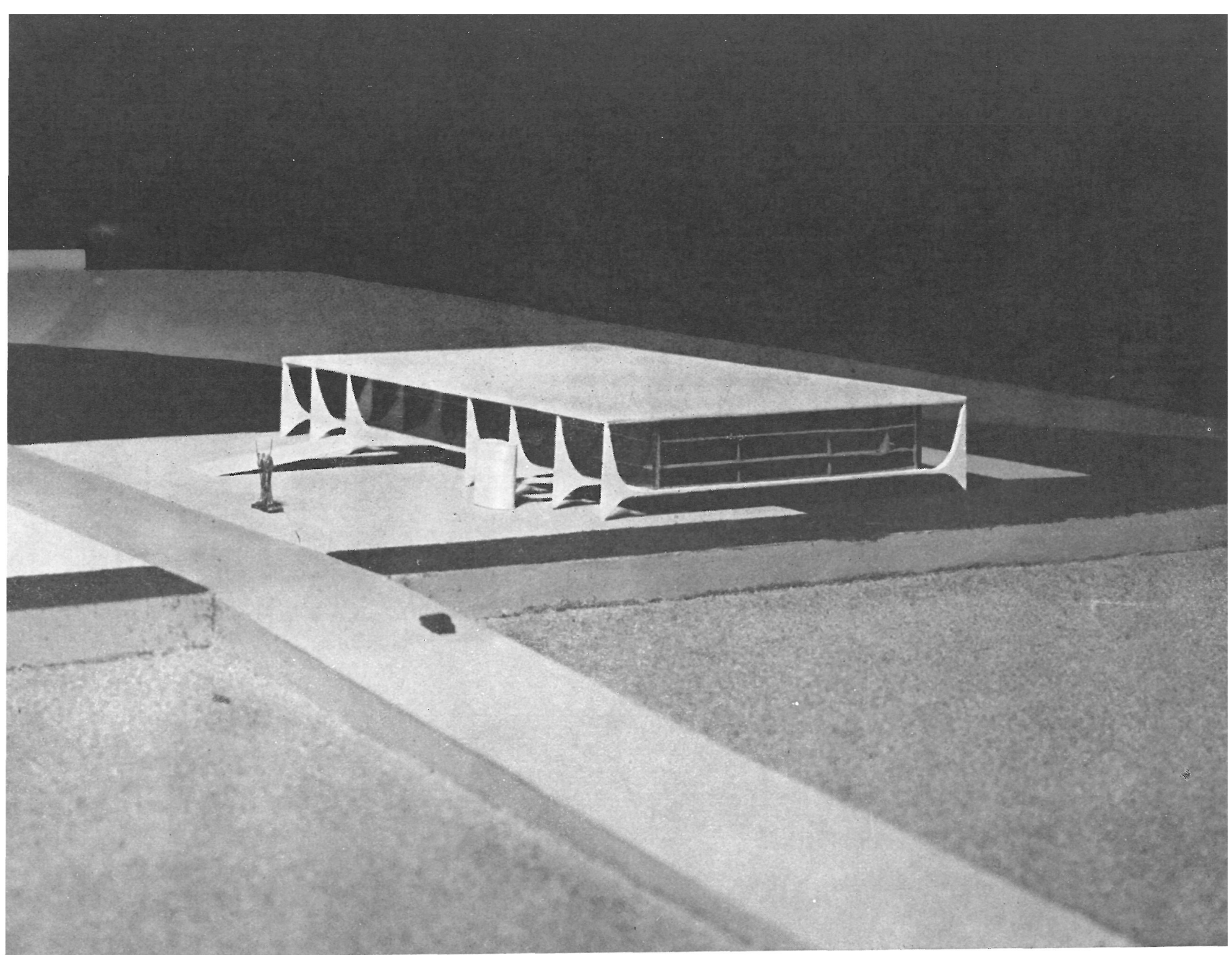

Palacio Alvorada, residencia oficial del Presidente del Estado, en Brasilia (1956-1958). Oscar Niemeyer, arquitecto.

Palacio del Presidente; edificio de oficinas, en Brasilia (1956-1958). Oscar Niemeyer, arquitecto.

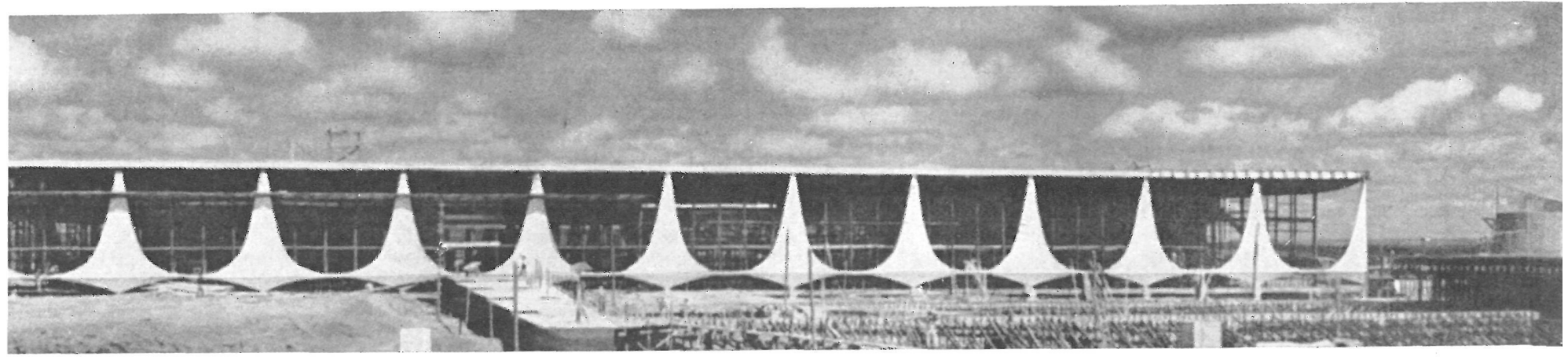




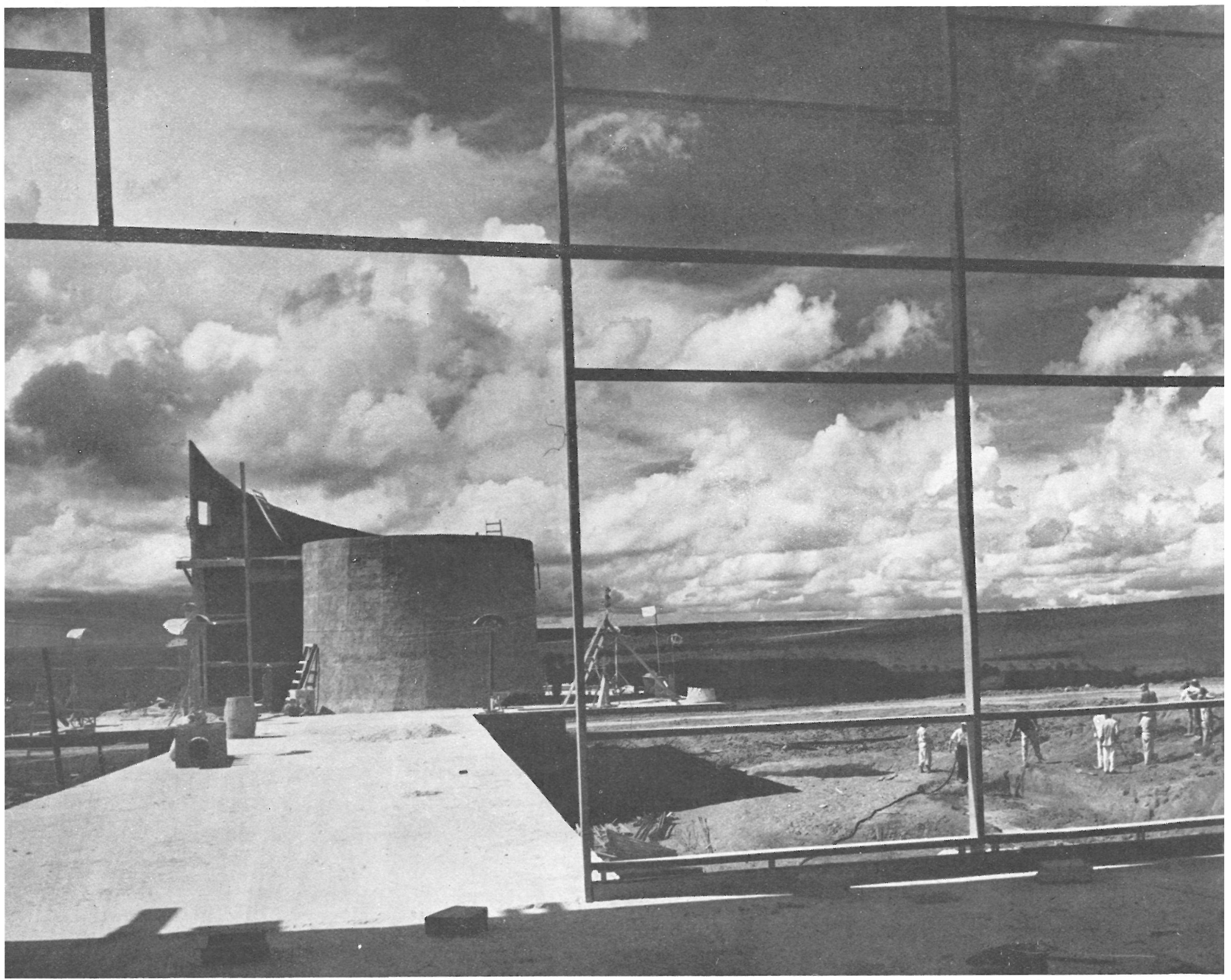

Gapilla presidencial, en Brasilia (1956-1958). Oscar Niemeyer, arquitecto.

Lucjan Korngold ha erigido, en 1947-1950, el edificio con estructura de hormigón armado más alto de América: el de la "Compañía de Bloqueos Explanada", en Río de Janeiro. Ahora este país quiere transformar su topografía y sus condiciones económicas trasladando la sede de sus poderes públicos. Con Brasilia - cuya planta piloto ha sido concebida por el genio de Lucio Costa-, una nueva ciudad reemplazará a Río de Janeiro y marcará el triunfo de la ciudad futura y del urbanismo funcional.

La capital de Brasil dejará la costa atlántica para organizarse eficazmente en el centro de gravedad de un territorio inmenso, en la provincia de Goiás. Gracias a una arquitectura auténtica, Brasil va a encontrar una verdadera ansia nacional que le permitirá modificar enteramente su fisonomía industrial y rural.

Debemos subrayar que, después de haberse relacionado con las grandes corrientes europeas del arte moderno, la arquitectura brasileña de hoy ha descubierto plenamente sus propias particularidades. Una de sus características más sobresalientes es la de poner todo su esfuerzo en la resolución de los problemas prácticos con un ideal de grandeza que hay que satisfacer. Como todas las arquitecturas del mundo, la arquitectura brasileña tiene también sus aberraciones, pero la tendencia funcionalista-la cual está sostenida por las mayores autoridades del país-no tiene los menores rasgos de ellas. Esto revela el ardor maravilloso de la invención y de la creación.

Puesto que Brasil ha encontrado su verdadero camino y su arquitectura ha superado el obstáculo de la incomprensión, sería injusto no aplaudir la obra extraordinaria realizada por sus temerarios pioneros y sus iniciadores perspicaces. 


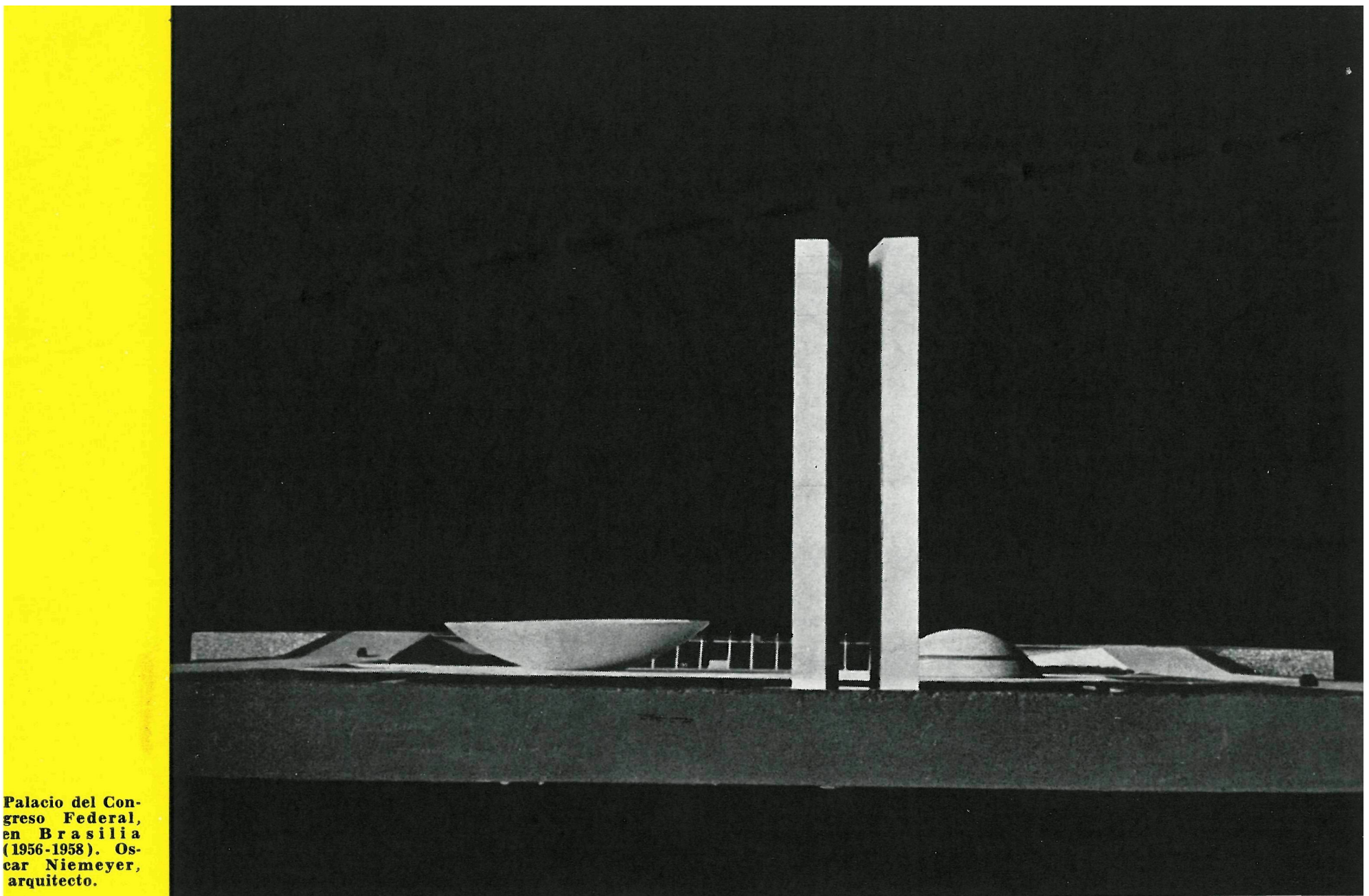

arquitecto.

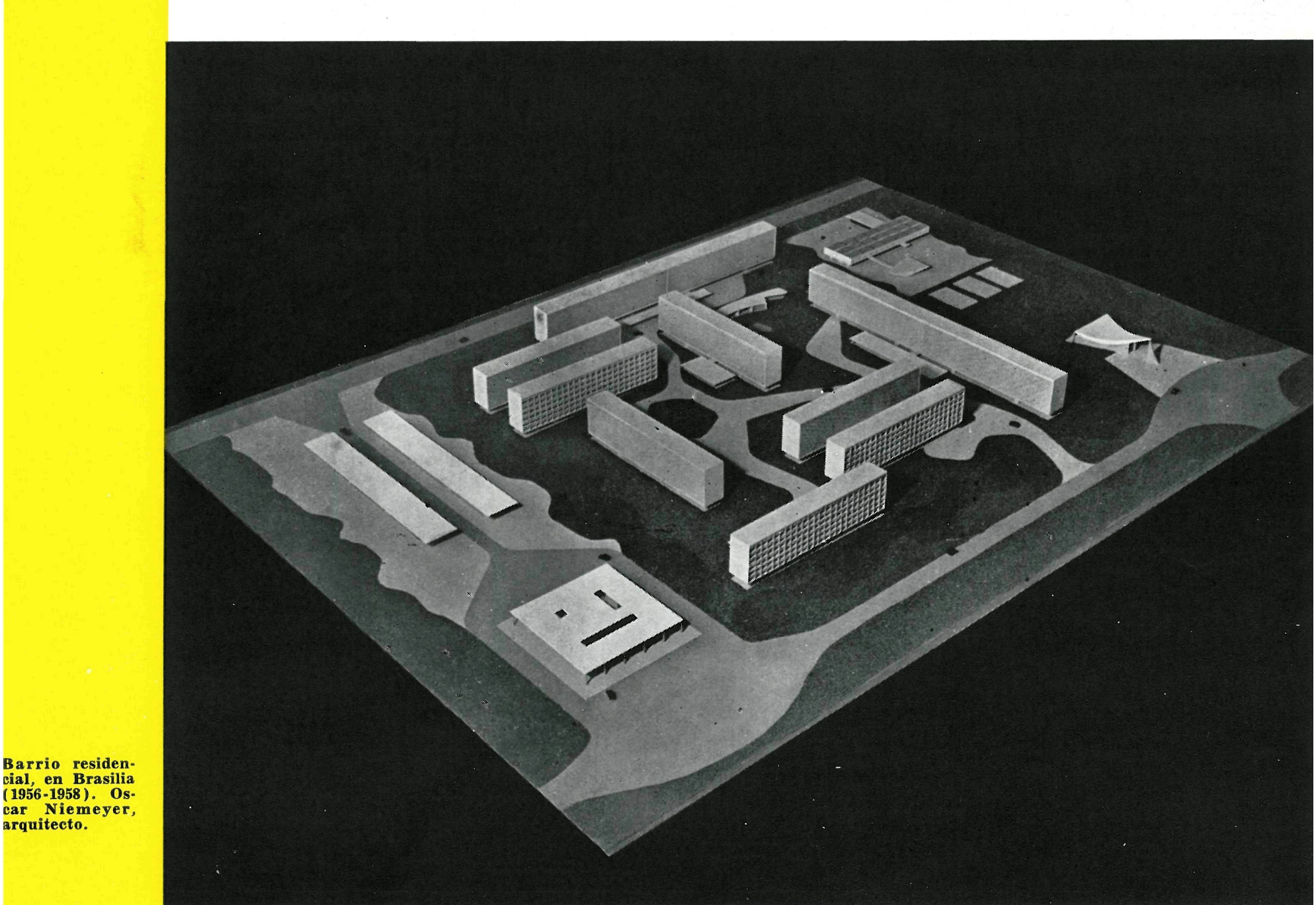




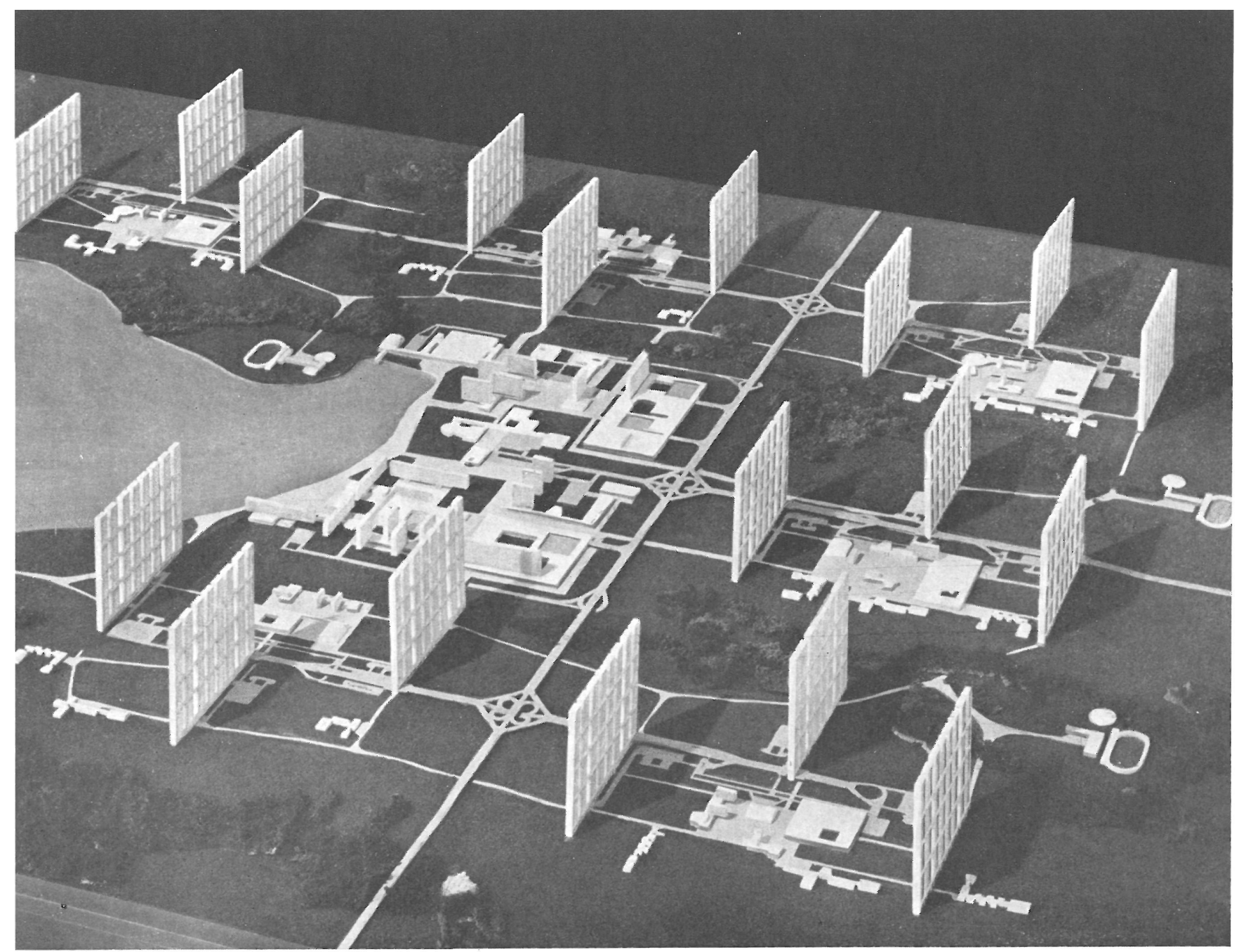

Proyecto de la planta piloto desarrollada por los arquitectos Rino Levi, Roberto Cerqueira y L. R. Carvalho, que obtuvo el segundo premio, en el convocado para el desarrollo de la nueva capital

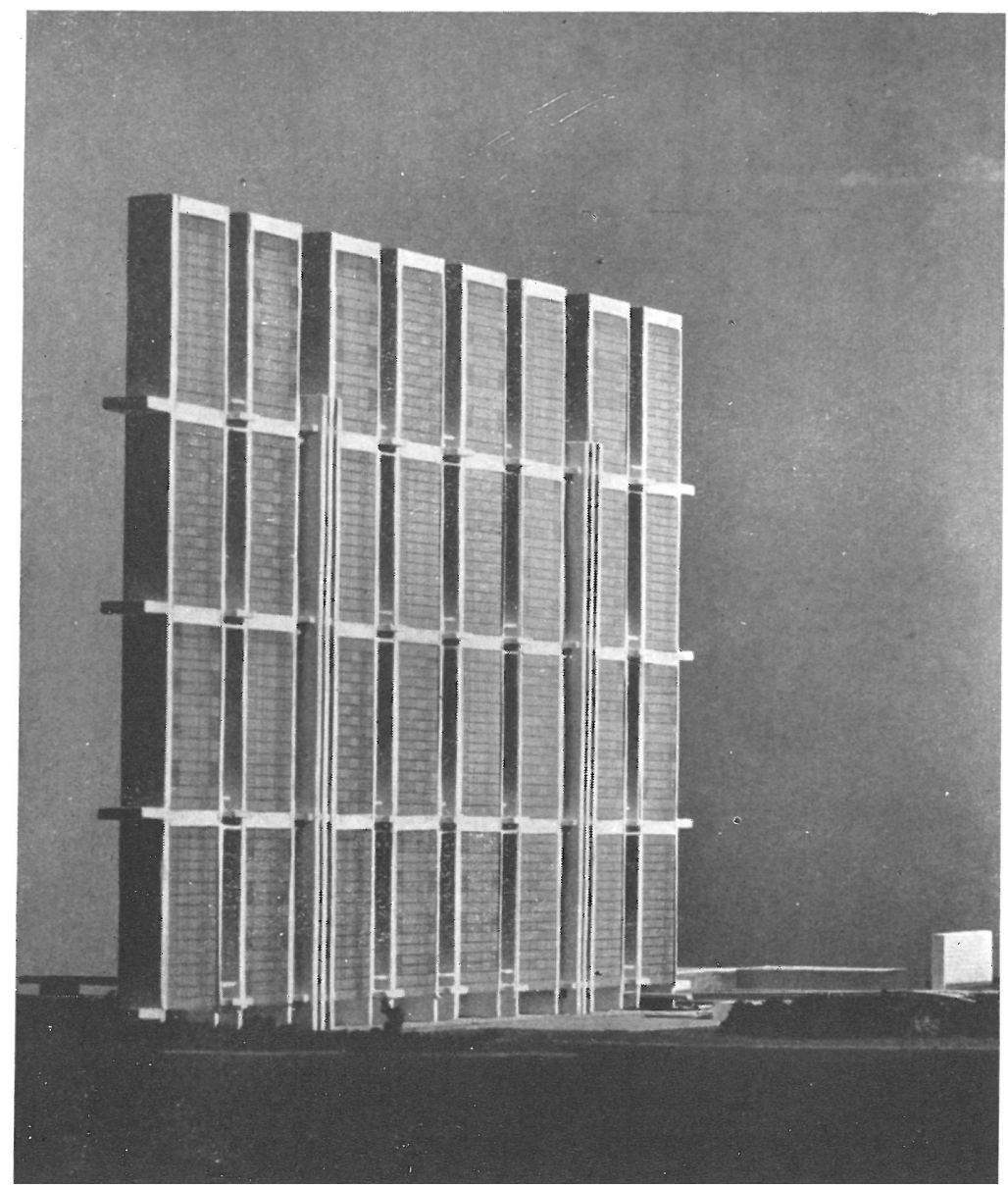

